\title{
SIGNATURES OF BRAIN PLASTICITY SUPPORTING LANGUAGE RECOVERY AFTER PERINATAL ARTERIAL ISCHEMIC STROKE
}

Clément François ${ }^{1}$, Alfredo Garcia-Alix ${ }^{2,3,4}$, Laura Bosch ${ }^{3,5,6}$, Antoni Rodriguez-Fornells s $^{7,8}$

${ }^{1}$ Aix Marseille Univ, CNRS, LPL, (13100) Aix-en-Provence, France

${ }^{2}$ Service of Genetic and Molecular Medicine, Hospital Sant Joan de Déu, Barcelona, Spain ${ }^{3}$ Institut de Recerca Sant Joan de Déu, Barcelona, Spain

${ }^{4} \mathrm{NeNe}$ Foundation, Madrid, Spain

${ }^{5}$ Department of Cognition, Development and Educational Psychology, University of Barcelona, Barcelona, Spain

${ }^{6}$ Institute of Neurosciences (UBNeuro), University of Barcelona, Barcelona, Spain ${ }^{7}$ Cognition and Brain Plasticity Group, IDIBELL, L’Hospitalet de Llobregat, Barcelona, Spain ${ }^{8}$ Catalan Institution for Research and Advanced Studies, ICREA, Barcelona, Spain

*Corresponding author:

Clément François, Laboratoire Parole et Langage, CNRS, Aix-Marseille University, 5 avenue Pasteur, 13100, Aix-en-Provence, France. Phone: (+33) 413552714.

Email: clement.francois@univ-amu.fr 


\begin{abstract}
Brain imaging methods such as functional Magnetic Resonance Imaging (fMRI) and Diffusion Tensor Imaging (DTI) have already been used to decipher the functional and structural brain changes occurring during normal language development. However, little is known about the differentiation of the language network after an early lesion. While in adults, stroke over the left hemisphere generally induces post-stroke aphasia, it is not always the case when a stroke occurs in the perinatal period, thus revealing a remarkable plastic power of the language network during early development. In particular, the role of perilesional tissues, as opposed to undamaged brain areas in the functional recovery of language functions after an early insult, remains unclear. In this review article, we provide an overview of the extant literature using functional and structural neuroimaging data revealing the signatures of brain plasticity underlying near-normal language development.
\end{abstract}




\section{Introduction}

In adults, language processing relies on a largely distributed network mainly involving the perisylvian areas of the left hemisphere interconnected through the dorsal and ventral pathways (Catani et al., 2005; Price, 2012). This dual-stream network for language processing includes the dorsal pathway that connects frontal, parietal and temporal areas (Hickok \& Poeppel, 2004). This pathway mainly involves the arcuate fasciculus (AF) composed of three segments, the long, the anterior and the posterior segments (Catani et al., 2005). The dorsal stream has been shown to play a crucial role in sensory to motor transformations (Saur et al., 2008; Schmahmann et al., 2007), in verbal short-term memory (Liberman \& Mattingly, 1985), in syntactic processing (Brauer et al., 2011; Friederici et al., 2006; Berwick et al., 2013) and novel word learning (López-Barroso et al., 2013; Rodriguez-Fornells et al., 2009; Cunillera et al., 2009). The ventral pathway, instead, connects the temporal, the occipital and the frontal lobes through the inferior longitudinal fasciculus, the inferior frontal-occipital fasciculus and the uncinate fasciculus (Catani \& Thiebaut de Schotten, 2008). This ventral stream has been shown to mainly support speech comprehension and semantic learning by contributing to the mapping of phonological into semantic representations (Saur et al., 2008; Hickok \& Poeppel, 2004; Ripollés et al., 2017).

In adults, the disruption of the dorsal part of the speech network due to stroke can induce conduction aphasia which is mainly characterized by word repetition deficits (Wernicke, 1874; Kümmerer et al., 2013). By contrast, stroke occurring during the perinatal period over the left hemisphere generally does not induce post-stroke aphasia thus suggesting that brain plasticity can support functional recovery (Bates et al., 2001; Stiles et al., 2005). Interestingly, the speech network is still developing at the time of the insult, as recent neuroimaging studies, conducted in healthy infants, have revealed different maturational time course of grey and white matter components (see Dehaene-Lambertz, 2017; Yu et al., 2019; Ouyang et al., 2019). In this context, the study of children with perinatal arterial ischemic stroke (PAIS) provides a unique opportunity to show the signatures of brain reorganization and plasticity mechanisms occurring 
before language functions are acquired. From a biological perspective, developmental studies provide an excellent level of analysis to understand language acquisition and the gradual unfolding of language functions in the brain (Tinbergen, 1963; MacDougall-Shackleton, 2011; Hladký \& Havlíček, 2013). In this review article, we present a brief overview of the neuroimaging studies revealing the progressive maturation of the speech network during normal development. We follow by illustrating the two most prevalent hypotheses explaining the functional recovery of language functions after an early brain lesion, with a focus on studies using neuroimaging methods in children with PAIS.

\section{Early development of the speech network}

From a developmental perspective, during the first years of life, the brain is the place of very dynamic structural and functional changes that support the acquisition of increasingly complex linguistic abilities (Dehaene-Lambertz, 2017; Dehaene-Lambertz \& Spelke, 2015; Catani \& Bambini, 2014). The recent SCALED model (for "Social Communication And Language Evolution and Development") presents neuroanatomical and neurolinguistic data integrated into developmental and evolutionnary frameworks (Catani \& Bambini, 2014). Specifically, the model describes five developmental stages of increasing linguistic complexity that may be supported by the gradual maturation of specific brain networks and their corresponding white matter pathways. Of particular interest here are the first, third and fourth developmental stages focusing on (i) early perception and production, (ii) lexical and semantic processing, and (iii) syntactic processing in language development. This model is grounded on the results of behavioural studies that have revealed that language experience modifies infants' early perceptual sensitivity to speech sounds in such a way that native sound discrimination gradually refines while nonnative speech sound perception decreases by the end of the first year of life (Kuhl et al., 2006, 2008; Werker, Yeung, \& Yoshida, 2012). Interestingly, language production skills also emerge and refine in the second half of the first year following a rather similar developmental trajectory. Canonical babbling, beginning around 6-8 months of age, starts to present language-specific properties by the end of the first year of life as reflected by increasing 
quality and tuning of speech sounds (Kuhl \& Meltzoff, 1996). These acquisition processes may require the maturation of the the dorsal pathway connecting posterior superior temporal, inferior parietal and inferior frontal regions. Specifically, the long segment of the AF connecting speech perception to spech production brain areas seems to be crucial for the proper development of linguistic skills (Lebel \& Beaulieu, 2009; Budisavljevic et al., 2015). In adults, this pathway supports auditory-motor integration processes involved in word repetition, phonological shortterm memory and novel word learning (Rodriguez-Fornells et al., 2009; Lopez-Barroso et al., 2013). Interestingly, DTI studies in young infants show that plastic changes through fiber pruning exist at least until the end of the first postnatal year (Dubois et al., 2008, 2015; Takahashi et al., 2012). Studies in healthy newborns even suggest a protracted growth of the long segment of the AF (Brauer et al., 2013; Perani et al., 2011; Zhang et al., 2007). These results converge with previous ones pointing to a more graded maturation of the dorsal whitematter tracts supporting language processing, particularly when compared to the maturation of the ventral pathway connecting the superior temporal, angular gyrus and inferior frontal gyri through the inferior fronto-occipital, inferior longitudinal and uncinate fasciculi (Brauer et al., 2013; Dubois et al., 2015; Bajada, Lambon-Ralph \& Cloutman, 2015). Recent DTI results point to a similar developmental pattern for white-matter pathways connecting temporo-parietal and frontal regions via the Superior Longitudinal Fasciculus (SLF, Yu et al., 2019; Ouyang et al., 2019). Therefore, the changes observed in the long segment of the AF, as well as those in the anterior segment of the AF (connecting frontal and inferior-parietal regions) might be crucial for early language acquisition. Finally, the SCALED model also proposes that the functional maturation of ventral temporal frontal networks, known to be involved in lexical and semantic processes (Friederici et al., 2006, 2010; Mesgarani et al., 2014; Price, 2012; Wilson et al., 2011), may support the vocabulary spurt occurring during the second year of life (Goldfield \& Reznick, 1990; Schafer \& Plunkett, 1998).

In terms of functional activations, functional Magnetic Resonance Imaging (fMRI) has been used to show that newborns and young infants bilaterally activate fronto-temporal areas with a 
right predominance in the auditory cortices when presented with infant-directed speech (Dehaene et al., 2002, 2006; Perani et al., 2011). Older children between 5 and 6 years of age exhibit left fronto-temporal functional activations during passive story listening paradigms (Hutton et al., 2018; Romeo et al., 2018, see also Weiss-Croft \& Baldeweg 2015, for a systematic review on the maturation of language networks based on fMRI studies). Taken together, these studies show that the gradual development of language abilities from early perception to word production and lexical and morphosyntactic learning is supported by the progressive development and maturation of the language brain network (Catani \& Bambini, 2014). In this context, the study of children with perinatal brain lesions offers a good model of early brain reorganization. In the following section, we illustrate the two prevalent theories explaining near-normal development after PAIS.

\section{Neuroimaging markers of language recovery after perinatal arterial ischemic stroke}

PAIS occurs in about one in 4000 births (Nelson \& Lynch, 2004) and can have long-term negative effects on cognitive and language development. Children with unilateral PAIS often show lower academic achievement scores than typically-developing peers (Ballantyne et al., 2008) and they generally present individual differences in their degree of language recovery with low to near-normal language development (Fuentes et al., 2014; Murias et al., 2014; Anderson et al., 2011; Bates et al., 2001; Stiles et al., 2005). This might be partly explained by the fact that children with PAIS present highly reorganized brain networks with language regions being consistently affected. Moreover, the presence of epileptic seizures, altered resting state networks (see Figure 1), as well as differences between early normal brain maturation and cellular mechanisms induced by the lesion may also explain the cognitive and language impairments often observed in these children. 


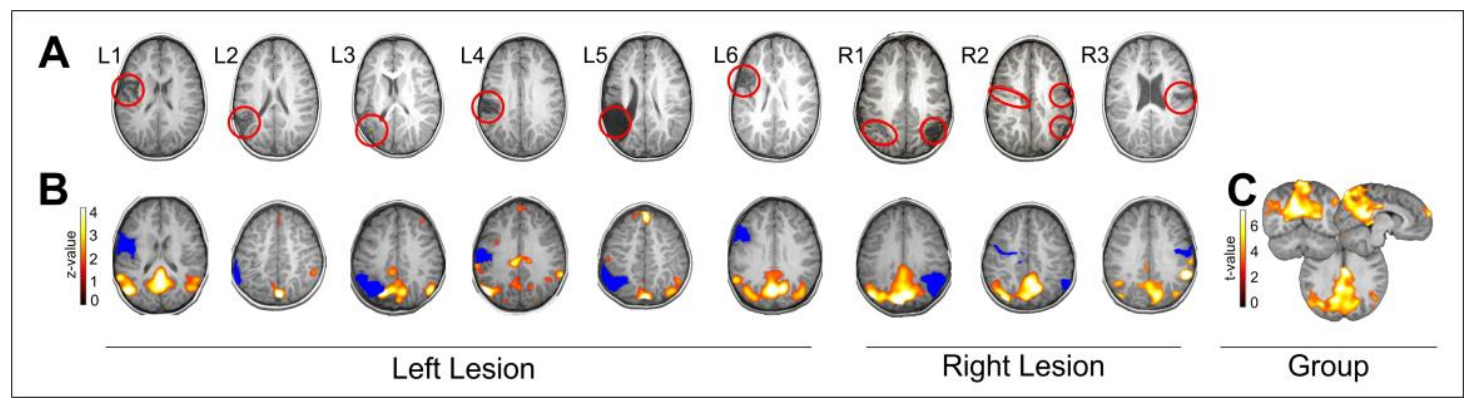

Figure 1. (A) Structural lesions of 9 children with left or right/bilateral PAIS shown in native space using a T1-weighted axial image. The lesions are highlighted with a red circle. Neurologic convention is used. (B) Individual Default-Mode Networks obtained using Group Spatial ICA on the resting state data obtained under propofol anesthesia. Individual data is in z-scores ( $\mathrm{p}<0.05$, uncorrected) and presented over each patient's T1 registered to a common space (4-year-old MRI brain template obtained from the Neurodevelopmental MRI Database). (C) The group averaged DMN for all patients is depicted (using t-values, $(\mathrm{p}<0.01$, uncorrected) over a canonical 4-year-old MRI brain template (adapted from François et al., 2019).

Using multimodal neuroimaging data acquired during the first week of life of 34 infants with unilateral or bilateral PAIS, it has been recently found that parietal posterior brain regions largely involved in language processing are the most affected in neonatal stroke (Stephan-Otto et al., 2017; see also Núñez et al., 2019). These early lesions seem to mainly affect the dorsal stream of language processing (especially the long segment of the AF, see Figure 2). Therefore, the question about how the developing brain compensates and reorganizes after an early lesion in order to achieve near-normal language proficiency remains open.

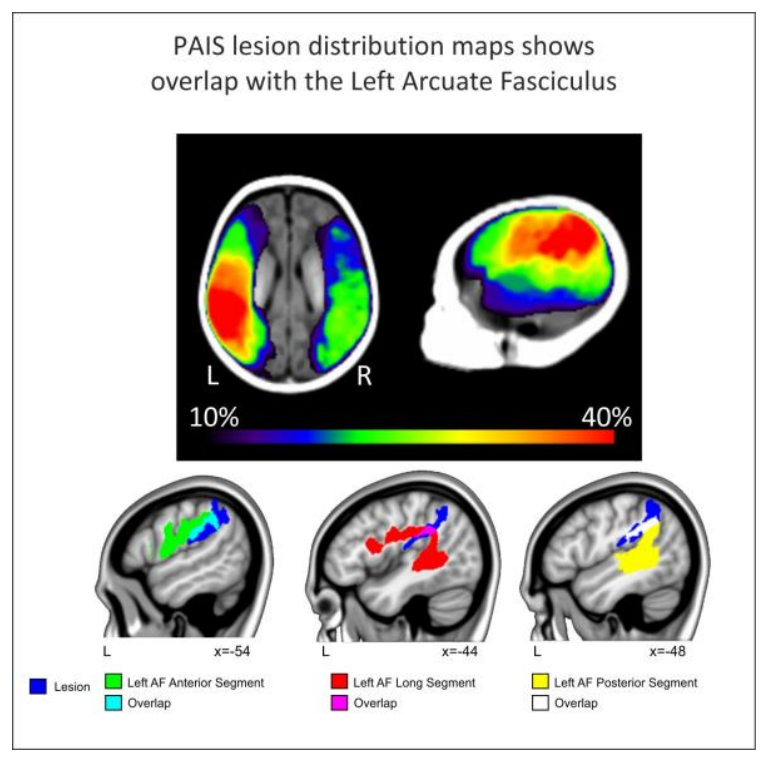

Figure 2. Top: Lesion maps of 34 newborns with PAIS adapted from Stephan-Otto et al., 2017 (A and B). Bottom: Overlap between the different segments of the arcuate fasciculus and the NAIS map. The probabilistic neonatal arterial ischemic stroke (NAIS) map (Stephan-Otto et al., 2017) was created by registering 34 neonatal patients to a neonatal high-resolution brain template (Sanchez et al., 2012). We first linearly registered this neonatal template to the MNI152 space using FLIRT (FMRIB's Linear Image Registration Tool; Jenkinson et al., 2012). Then we used 
FNIRT to non-linearly register the neonatal to the adult template. The parameters obtained during these calculations were applied to the NAIS map to register it to standard space. The region in which at least $50 \%$ of the NAIS overlapped in the left hemisphere is depicted in dark blue. Probability templates for the long (in red, overlap with the lesion in pink), anterior (in green, overlap with the lesion in light blue) and posterior (yellow, overlap with the lesion in white) segments of the arcuate were extracted from the Tractotron atlas (Rojkova et al., 2015; Thiebeaut de Schotten et al., 2011) and were thresholded at a 50\% (only voxels having a 50\% probability of being part of the AF according to the atlas are shown). Results are overlaid over a canonical template in MNI space, with coordinates at the bottom right of each slice.

First, there is evidence showing that early left hemisphere lesions can trigger the transfer of language functions in homologous brain regions of the right hemisphere (Tillema et al., 2008; Jacola et al., 2006; Ilves et al., 2014; Guzzetta et al., 2008; Lidzba et al., 2017a; François et al., 2016, 2019). For instance, Jacola and colleagues (2006) used fMRI with both a verb generation and a passive story listening task in three children aged 7,9 and 10 years with unilateral left PAIS of the middle cerebral artery (MCA; see Table 1 for a summary of the neuroimaging studies on perinatal stroke). Compared to controls, children with PAIS showed atypical brain activations with a clear engagement of the right homologous regions (Jacola et al., 2006). In another fMRI study, Tillema and collaborators (2008) evaluated ten children with unilateral left PAIS using a verb generation task and revealed a similar pattern of right-sided BOLD activation over Broca's area. These studies have brought evidence suggesting that the undamaged righthemisphere can take-over language functions probably via inter-hemispheric transfer of functions.

There is also evidence showing that the remaining of functionally active left hemisphere brain regions can be associated with better language outcomes (Raja-beharelle et al., 2010; Dick et al., 2013). Using a category fluency task in a large sample of children with left PAIS ( $\mathrm{N}=25)$, Raja-Beharelle and colleagues (2010) showed that preserved activation of the left frontal regions was associated with better linguistic outcomes than fully right-lateralized activations. By contrast, in the case of children with lesions over the temporal-parietal regions, they observed that bilateral activations within these areas were associated with better outcomes than fully right-lateralized participants.

The functional recovery of language functions after PAIS may therefore depend on the type of brain mechanisms involved, in particular on the role of perilesional as opposed to 
homologous brain areas of the unaffected hemisphere. Several factors must be considered to explain the different outcomes observed in the case of intra vs. inter-hemispheric transfer of function. First, the type of lesion is a crucial factor. For instance, almost half of the children included in the Raja-Beharelle and collaborator's study had periventricular venous infarction (PVI) which is known to induce smaller linguistic and cognitive deficits than children with PAIS (Kirton et al., 2008). The presence of altered functional connectivity at rest is also an important factor. Indeed, there is recent evidence showing that children with left PAIS present altered default-mode resting-state networks (François et al., 2016; 2019) whereas children with PVI may have a preserved functional connectivity compared to controls (Ilves et al., 2016; Carlson et al., 2019). The size and type of the lesions are further crucial factors. Indeed, PVI generally induces more focal sub-cortical lesions compared to PAIS of the MCA (Kirton et al., 2008). Taken together, these results argued against the right hemisphere take-over hypothesis and rather suggested an intra-hemispheric transfer of function that may be subsumed by perilesional tissues (Anderson et al., 2011). This pattern of results is consistent with the recovery of motor functions in adult individuals with stroke, in which the restoration of brain activity in the affected hemisphere and decreased activation in the non-affected one predicts better motor outcomes than bilateral and/or contralesional activations (Jaillard et al., 2005; Carey et al., 2005; Grefkes et al., 2008). These observations in the motor domain have led to propose the bimodal balance-recovery model in which intra-, as opposed to inter-hemispheric reorganization, depends on the individual's structural reserve to support a particular function (Di Pino et al., 2014).

Importantly, most of these studies have shown a strong interaction between the size, the location, and the type of lesion as determinant factors for functional recovery (see Anderson et al., 2011). Future research is needed to better understand the role of these factors in triggering either intra-hemispheric or inter-hemispheric plasticity mechanisms as well as in inducing functional recovery of language or not. Unfortunately, most of these studies were conducted in very heterogeneous groups of patients in terms of age-range with language functions generally 
evaluated after an eventual "catch-up" induced by schooling. Besides, despite an effort to thoroughly evaluate subtle language functions at the behavioural level (Reilly et al., 2013; Demir et al., 2010, 2013, 2015; Westmacott et al., 2010), combined functional and structural neuroimaging data together with fine-grained behavioral assessments are still very scarce in this population.

Diffusion tractography allows the study of the microstructural properties of white matter tracts such as the arcuate fasciculus in a non-invasive manner (see Le Bihan, 2003 for a review). This method is particularly relevant in pediatric populations such as extremely premature infants, or children with cortical malformations. Results have suggested a link between the microstructural properties of the arcuate fasciculus and language abilities (Salvan et al., 2017; Paldino et al., 2015). However, to our knowledge, only a few studies have gathered structural MRI together with behavioural and neuropsychological data in children with PAIS (François et al., 2016, 2019; Northam et al., 2018, see Figure 3 for a summary of the main results of the two last studies).

In a single-case study, a 3.5-year-old boy with a unilateral left perinatal stroke of the MCA was assessed with both functional and structural MRI as well as with an exhaustive battery of language outcomes with measures of receptive vocabulary, phonological whole-word production, and linguistic complexity in spontaneous speech. In addition, word learning abilities were assessed using a fast-mapping task designed to assess the immediate and delayed recall of newly mapped words (François et al., 2016). Fast-mapping tasks have been originally designed to evaluate the ability to associate novel word forms with unfamiliar objects based on the observation that young children can learn and retain the names of new objects after very limited exposure to those novel labels, a process underlying vocabulary acquisition in early childhood (Carey \& Bartlett, 1978). Neuroimaging data of that single-case study (François et al., 2016) revealed a right-lateralized pattern of activation during a passive story listening task and a disrupted left AF. Receptive vocabulary measured with the Peabody Picture Vocabulary Test, PPVT-III (Dunn \& Dunn, 1997), fell within normal limits but whole word production was 
delayed, and the child had limited spontaneous speech. Critically, the child showed clear difficulties in both the immediate and delayed recall of the words in the word learning task, significantly differing from controls in the retention of new word-referent associations. These data were in line with previous results in healthy adults (López-Barroso et al., 2013) and suggested a crucial role of the left $\mathrm{AF}$ in the learning of novel word-referent associations in young children. In a further study, François and colleagues (2019) studied a group of six 4-y-o children with unilateral left PAIS who were assessed with a comprehensive battery of cognitive and linguistic outcomes with both productive and receptive aspects of language (see Table 1) as well as with a multimodal neuroimaging battery including the collection of functional activations during a passive story listening paradigm (fMRI), at rest (rs-fMRI) as well as the collection of DTI data. Despite a small sample size, the results were clear cut in showing right lateralized functional activations during the passive story listening paradigm as well as disruptions of the left AF. Importantly, the results showed significant associations between productive aspects of language functions and (i) structural reorganization of the dorsal pathway (i.e. the right lateralization of the volume of the $\mathrm{AF}$ ) and (ii) functional reorganization of the dorsal pathway (i.e. the right lateralization of the functional connectivity at rest between the superior temporal gyrus and the inferior frontal gyrus; see Figure 3C).

Another recent study gathered functional and structural MRI data as well as various standardized neuropsychological tests evaluating perception and production of language in 21 children with left neonatal stroke (Northam et al., 2018). Results showed that an early lesion of the dorsal pathway together with left-lateralized functional activations during a verb generation task was associated with impaired nonword and verbatim sentence repetition like conduction aphasia in adults. On the contrary, children with right-lateralized functional activations were less impaired in word repetition (see Figure 3D). Besides, atypical lateralization of cerebellar activations towards the left was also predictive of repetition performance. In adults, speech production task induces consistent cerebellar activations contralateral to the typical language dominant brain network (Jensen et al., 2005). In the study from Northam and colleagues (2018), 
while patients with typical activations of the left fronto-temporal language network together with right cerebellar activations showed poor speech repetition abilities, the group of patients with a mirrored pattern of activations at the cortical and cerebellar levels (i.e. activations of the right fronto-temporal network and left cerebellum) showed better outcomes. The authors suggested the possible existence of a developmental form of conduction aphasia characterized by a persistent deficit in speech repetition but occurring after neonatal stroke (Northam et al., 2018). However, these results obtained in such a cross-sectional design did not provide information about the time course of the reorganization process. Nonetheless, they are in line with recent observations in a cohort of 4-year-old children with unilateral left PAIS in which a right-lateralized arcuate fasciculus as measured by the laterality index of the AF volume was associated with better expressive language based on utterance length (see Figure 3C; François et al., 2019). Taken together, these last studies suggest that the redundancy and bilateral organization of the language network can leave room for the functional and structural brain reorganization supporting the near-normal development of language functions. 


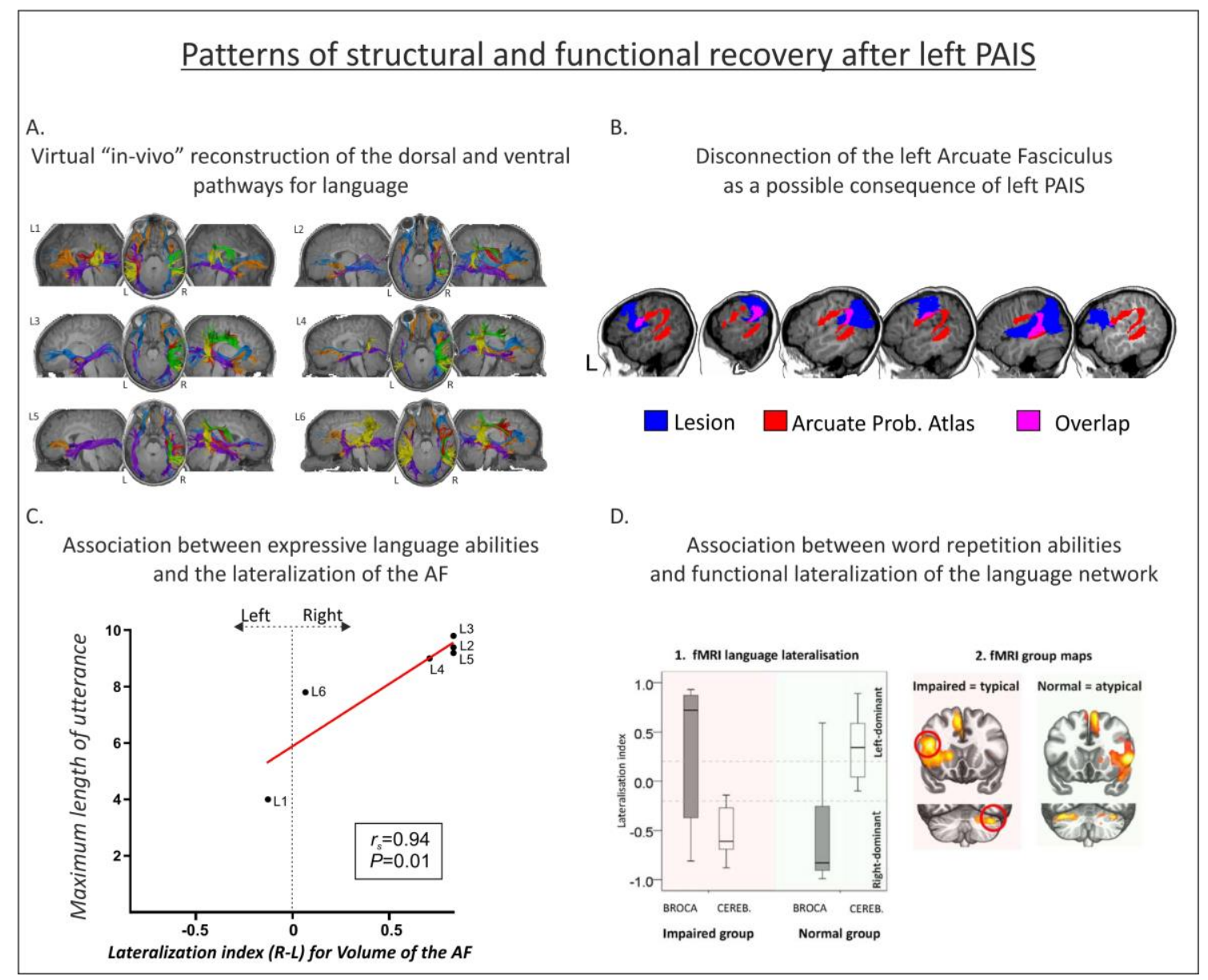

Figure 3. Examples of functional and structural reorganization after left PAIS. A) T1 image and 3D reconstructions of the AFs in a group of 4-y-o children with left MCA stroke using deterministic tractography (Adapted from François et al., 2019). B) Overlap of the different segments of the AF and the lesion mask (adapted from François et al., 2019). The lesion mask is shown in dark blue. Probability templates for the long (in red, overlap with the lesion in pink), anterior (in green, overlap with the lesion in light blue) and posterior (yellow, overlap with the lesion in white) segments of the AF were extracted from the Tractotron atlas (Thi ebeaut de Schotten et al., 2011) and are thresholded at a 50\% (only voxels having a 50\% probability of being part of the AF according to the atlas are shown). C) Association between the lateralization of the volume of the Arcuate Fasciculus and expressive language abilities as measures by the mean length of utterance (from François et al., 2019). D) Association between the lateralization of activations obtained during a verb generation task (laterality index) and word repetition abilities (left) with the corresponding activation maps (right) adapted from Northam et al., 2018. STG, Superior Temporal Gyrus; SMA, Supplementary Motor Area; IFG, Inferior Frontal Gyrus; SMG, Supramarginal gyrus; ANG, Angular Gyrus; STG, Superior Temporal Gyrus.

However, care must be taken when dealing with neuroimaging data obtained from lesioned brains, especially in pediatric populations. A first concern lies with the fact that group analyses, especially for fMRI but also for DTI data (see Tract-Based Spatial Statistics; Smith et al., 2006), are computed in standard spaces. The pre-processing of MRI data can involve different normalization techniques of the individual brain data to adult atlases which are known to show several limitations (e.g., misalignments, changes in the relation between micro- and macrostructural aspects; see Brett et al., 2001; Crinion et al., 2007; Altaye et al., 2008). While 
specific steps can be taken to minimize these normalization errors (e.g., cost function masking; Andersen et al., 2010; Ripollés et al., 2012), another solution is to analyze the data in native space. This latter option is very common in DTI, where laterality measures can be calculated by virtually dissecting white matter tracts in native space (Thiebaut Schotten et al., 2011), without transforming the original data. Such an approach has been successful in revealing brain to behavior relationships in children with unilateral left PAIS (François et al., 2016, 2019). Besides, the presence of lesioned tissues with altered microstructure can negatively impact the functioning of algorithms estimating fiber orientation which can, in turn, lead to artifacts during track reconstruction (Ciccarelli et al., 2008; Dell'acqua et al., 2010). In this regard, an interesting approach is the development of detailed brain atlases and templates of children at different ages to compute region of interest analyses. While great advances have been made (see Neurodevelopmental MRI Database http://jerlab.psych.sc.edu/NeurodevelopmentalMRIDatabase/access.html; Almli et al., 2007; Sanchez et al., 2011; Richards et al., 2015; Fillmore et al., 2015), further research is needed in order to obtain more precise atlases derived, for example, from cytoarchitectonic studies. 


\begin{tabular}{|c|c|c|c|c|c|c|c|c|}
\hline & $\begin{array}{c}\text { Sample } \\
\text { size } \\
\text { age at scan }\end{array}$ & $\begin{array}{c}\text { etiology } \\
\text { characteristics }\end{array}$ & $\begin{array}{c}\text { Hemisphere of } \\
\text { injury (left, right, } \\
\text { or bilateral) }\end{array}$ & fMRI task & Main results & DTI & Resting state & Language outcomes \\
\hline $\begin{array}{l}\text { Staudt } \\
\text { et al., } 2002\end{array}$ & $\begin{array}{c}\mathrm{N}=5 \\
18-25 \mathrm{y}-\mathrm{o}\end{array}$ & $\begin{array}{l}\text { Unilateral Left } \\
\text { periventricular } \\
\text { brain lesions }\end{array}$ & Left & Word generation & Right activation & - & - & $\begin{array}{c}\text { Word chain task } \\
\text { (number of words produced) }\end{array}$ \\
\hline $\begin{array}{l}\text { Tillema } \\
\text { et al., } 2008\end{array}$ & $\begin{array}{l}\mathrm{N}=10 \\
6-16 \mathrm{y}-\mathrm{o}\end{array}$ & $\begin{array}{l}\text { Unilateral Left } \\
\text { MCA perinatal ischemic } \\
\text { stroke }\end{array}$ & Left & VG & Right activation & - & - & - \\
\hline $\begin{array}{l}\text { Raja- } \\
\text { Beharelle } \\
\text { et al., } 2010\end{array}$ & $\begin{array}{c}\mathrm{N}=25 \\
8-20 \mathrm{y}-\mathrm{o}\end{array}$ & $\begin{array}{c}\text { Unilateral Left } \\
\text { Vascular }(\mathrm{n}=14) \\
\text { Periventricular }(\mathrm{n}=11)\end{array}$ & Left & Category fluency & Right, Left or bilateral activation & - & - & $\begin{array}{c}\text { Expressive vocabulary test } \\
\text { PPVT-III } \\
\text { CELF III } \\
\text { (Expressive \& Receptive language scores) }\end{array}$ \\
\hline $\begin{array}{l}\text { Dick } \\
\text { et al., } 2013\end{array}$ & $\begin{array}{l}\mathrm{N}=14 \\
7-10 \mathrm{y}-\mathrm{o}\end{array}$ & $\begin{array}{c}\text { Unilateral Left } \\
\text { Periventricular }(\mathrm{n}=6) \\
\text { Vascular }(\mathrm{n}=8)\end{array}$ & Left & Audio-visual SL & - & - & - & $\begin{array}{l}\text { CELF III } \\
\text { (receptive language \& listening to paragraphs } \\
\text { subtests) } \\
\text { Johnson-Newport Grammaticality Judgement } \\
\text { task }\end{array}$ \\
\hline $\begin{array}{l}\text { Jacola } \\
\text { et al., } 2006\end{array}$ & $\begin{array}{c}\mathrm{N}=3 \\
7,9,12 \mathrm{y}-\mathrm{o}\end{array}$ & $\begin{array}{l}\text { Unilateral Left } \\
\text { MCA perinatal stroke }\end{array}$ & Left & $\begin{array}{l}\text { VG } \\
\text { SL }\end{array}$ & Bilateral or Right activation & - & - & - \\
\hline $\begin{array}{l}\text { Lidzba } \\
\text { et al., } 2017\end{array}$ & $\begin{array}{c}\mathrm{N}=19 \\
7-32 \mathrm{y}-\mathrm{o}\end{array}$ & $\begin{array}{c}\text { Unilateral Left } \\
\text { vascular (MCA, } n=8) \\
\text { periventricular }(\mathrm{n}=11)\end{array}$ & Left & $\begin{array}{c}\text { Beep story task } \\
\text { (comprehension) } \\
\text { Vowel Identification task } \\
\text { (production) }\end{array}$ & $\begin{array}{l}\text { Comprehension: right activation } \\
\text { in } 7 / 19 \text { patients } \\
\text { Production: right activation in } \\
16 / 17 \text { patients }\end{array}$ & - & - & - \\
\hline $\begin{array}{l}\text { Ilves } \\
\text { et al., } 2014\end{array}$ & $\begin{array}{l}\mathrm{N}=12 \\
6.3-13.8 \text { y-o }\end{array}$ & $\begin{array}{c}\text { Unilateral Left } \\
\text { vascular perinatal }(\mathrm{n}=7) \text { and } \\
\text { childhood stroke }(\mathrm{n}=5)\end{array}$ & Left & $\begin{array}{c}\mathrm{VG} \\
\text { Sentence comprehension }\end{array}$ & $\begin{array}{l}\text { Bilateral or Right activation for } \\
\text { perinatal stroke }\end{array}$ & - & - & $\begin{array}{c}\text { NEPSY } \\
\text { (expressive \& receptive language subtests) }\end{array}$ \\
\hline $\begin{array}{l}\text { Guzzetta } \\
\text { et al., } 2008\end{array}$ & $\begin{array}{l}N=10 \\
7-19 y-o\end{array}$ & $\begin{array}{l}\text { Left perinatal } \\
\text { arterial stroke }\end{array}$ & Left & Covert rhyme generation & Right, Left or bilateral activation & - & - & - \\
\hline $\begin{array}{l}\text { François } \\
\text { et al., } 2016\end{array}$ & $\begin{array}{c}\mathrm{N}=1 \\
3.5 \mathrm{y}-\mathrm{o}\end{array}$ & $\begin{array}{l}\text { Unilateral Left } \\
\text { MCA PAIS }\end{array}$ & Left & $\begin{array}{c}\text { SL } \\
\text { with anesthesia }\end{array}$ & RH activation & $\begin{array}{l}\text { Deterministic tractography } \\
\text { Disconnection of the AF }\end{array}$ & $\begin{array}{l}\text { ICA analysis using } \\
\text { GIFT toolbox } \\
\text { Right fronto-temporal } \\
\text { network }\end{array}$ & $\begin{array}{c}\text { BSID-III } \\
\text { PPVT-III } \\
\text { Spontaneous expressive language complexity: } \\
\text { pMLU; MLU \& phonological whole-word } \\
\text { proximity } \\
\text { Novel label-object mapping (FM) }\end{array}$ \\
\hline
\end{tabular}




\begin{tabular}{|c|c|c|c|c|c|c|c|c|}
\hline $\begin{array}{l}\text { François et } \\
\text { al., } 2019\end{array}$ & $\begin{array}{c}\mathrm{N}=6 \\
3.5 \mathrm{y}-\mathrm{o}\end{array}$ & $\begin{array}{l}\text { Unilateral Left } \\
\text { MCA PAIS }\end{array}$ & Left & $\begin{array}{c}\text { SL } \\
\text { with anesthesia }\end{array}$ & RH activation & Deterministic tractography & $\begin{array}{c}\text { Functional } \\
\text { Connectivity CONN } \\
\text { toolbox } \\
\text { Right-lateralized } \\
\text { temporo-frontal } \\
\text { network }\end{array}$ & $\begin{array}{c}\text { BSID-III } \\
\text { PPVT-III } \\
\text { Spontaneous expressive language complexity } \\
\text { pMLU; MLU \& phonological whole-word } \\
\text { proximity }\end{array}$ \\
\hline $\begin{array}{l}\text { Ilves } \\
\text { et al., } 2016\end{array}$ & $\begin{array}{c}\mathrm{N}=17 \\
7.6-17-9 \mathrm{y}-\mathrm{o}\end{array}$ & $\begin{array}{l}\text { Unilateral Left MCA } \\
\text { PAIS and periventricular } \\
\text { venous infarction }\end{array}$ & Left & Awake eyes open & - & - & $\begin{array}{c}\text { ICA analysis } \\
\text { Increased activation } \\
\text { of the default mode } \\
\text { network }\end{array}$ & - \\
\hline $\begin{array}{l}\text { Northam } \\
\text { et al., } 2018\end{array}$ & $\begin{array}{c}N=30 \\
7-18 y-0\end{array}$ & $\begin{array}{l}\text { Unilateral Left }(\mathrm{n}=21) \\
\text { Right }(\mathrm{n}=6) \text { and bilateral } \\
(\mathrm{n}=3) \text { ischemic/hemorrhagic } \\
\text { stroke }\end{array}$ & Left, Right, and Bilateral & VG & RH activation & $\begin{array}{l}\text { Probabilistic tractography } \\
\text { Disconnection of dorsal or } \\
\text { ventral streams }\end{array}$ & - & $\begin{array}{c}\text { CTOPP } \\
\text { (nonword repetition test) } \\
\text { CELF III } \\
\text { (sentence repetition subtest) } \\
\text { Expressive \& } \\
\text { Receptive One-Word Picture Vocabulary tests } \\
\text { Test for } \\
\text { Reception of Grammar }\end{array}$ \\
\hline $\begin{array}{l}\text { Carlson } \\
\text { et al., } 2019\end{array}$ & $\begin{array}{c}\mathrm{N}=32 \\
6.6-29.7 \mathrm{y}-\mathrm{o}\end{array}$ & $\begin{array}{l}\text { Unilateral Left MCA } \\
\text { PAIS ( } \mathrm{n}=17) \text { and } \\
\text { periventricular venous } \\
\text { infarction }(\mathrm{n}=15)\end{array}$ & $\begin{array}{l}\text { Left }(\mathrm{n}=21) \text { and Right } \\
\qquad(\mathrm{n}=11)\end{array}$ & - & - & - & $\begin{array}{c}\text { Functional } \\
\text { Connectivity CONN } \\
\text { toolbox } \\
\text { Similar right } \\
\text { functional } \\
\text { connectivity between } \\
\text { right IFG and STG } \\
\text { compared to controls }\end{array}$ & $\begin{array}{l}\text { Expressive language: NEPSY-II } \\
\text { (word generation test) } \\
\text { Receptive language: } \\
\text { WJ-III } \\
\text { (understanding directions subtest) } \\
\text { CVLT-C }\end{array}$ \\
\hline
\end{tabular}



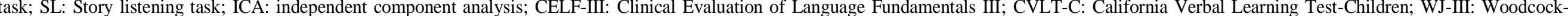



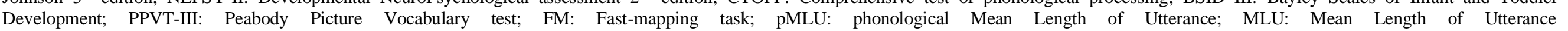




\section{Conclusion}

In conclusion, functional and structural neuroimaging studies in children with PAIS are of particular interest to better characterize which brain plasticity mechanisms better support the development of a complex human function such as language. The pattern of results emerging from this review indicates that two patterns of brain re-organization can be associated with good language outcomes after PAIS with (i) an inter-hemispheric re-organization with temporal and frontal language areas switching towards the right hemisphere, together with a possible reorganization of the cerebellum towards the left, and (ii) an intra-hemispheric re-organization with the involvement of functionally active perilesional brain regions. It also appears rather clear that studies including a thorough assessment of language functions are still very scarce. This is a limitation when aiming to demonstrate clinically valid linguistic recovery after early brain damage. Future studies using more complete assessments of language functions are thus needed. Finally, future research based on interventional designs or randomized clinical trials will certainly be of great help to better understand the neuroplasticity mechanisms allowing functional recovery after early brain injuries.

\section{Acknowledgments}

We would like to warmly thank Dr. Pablo Ripollés (New-York University) for helping us creating the figure 2. This work was funded by the "Plan Nacional de I+D+I and ISCIIISubdirección General de Evaluación y Fomento de la Investigación Sanitaria", Project PI15/00846 to AGA, the European Regional Development Fund (FEDER "a Way to Build Europe"), a SLT002/16/00390 grant, funded by the Department of Health of the Generalitat de Catalunya by the call "Acció instrumental d'incorporació de científics i tecnòlegs", a grant from the Bial Foundation to ARF and a Spanish MINECO project (PSI 2014-55105P) to LB.

\section{References}

Almli, C.R., Rivkin, M.J., McKinstry, R.C. (2007). Brain Development Cooperative Group. The NIH MRI study of normal brain development (Objective-2): newborns, infants, toddlers, and preschoolers. NeuroImage, 35(1), 308-325. 
Altaye, M., Holland, S.K., Wilke, M., Gaser, C. (2008). Infant brain probability templates for MRI segmentation and normalization. NeuroImage, 43, 721-730.

Andersen, S. M., Rapcsak, S. Z., \& Beeson, P. M. (2010). Cost function masking during normalization of brains with focal lesions: still a necessity? Neuroimage, 53, 78-84.

Anderson, V., Spencer-Smith, M., Wood, A. (2011). Do children really recover better? Neurobehavioural plasticity after early brain insult. Brain, 134(8), 2197-2221.

Ballantyne, A.O., Spilkin, A.M., Hesselink, J., Trauner, D.A. (2008). Plasticity in the developing brain: intellectual, language and academic functions in children with ischaemic perinatal stroke. Brain, 131(11), 2975-2985.

Bajada, C.J., Lambon Ralph, M.A., Cloutman, L.L. (2015). Transport for language south of the Sylvian fissure: the routes and history of the main tracts and stations in the ventral language network. Cortex, 69, 141-151.

Bates, E., Reilly, J., Wulfeck, B., Dronkers, N., Opie, M., Fenson, J., et al. (2001). Differential effects of unilateral lesions on language production in children and adults. Brain lang., 79(2), 223-265.

Berwick, R.C., Friederici, A.D., Chomsky, N., Bolhuis, J.J. (2013). Evolution, brain, and the nature of language. Trends in cognitive sciences, 17(2), 89-98.

Brauer, J., Anwander, A., Friederici, A.D. (2011). Neuroanatomical prerequisites for language functions in the maturing brain. Cereb. cortex, 21(2), 459-466.

Brauer, J., Anwander, A., Perani, D., \& Friederici, A. D. (2013). Dorsal and ventral pathways in language development. Brain Language, 127, 289-295.

Brett, M., Leff, A. P., Rorden, C., Ashburner, J. (2001). Spatial normalization of brain images with focal lesions using cost function masking. Neuroimage, 14, 486-500.

Budisavljevic S., Dell'Acqua F., Rijsdijk F.V., Kane F., Picchioni M., McGuire P., Toulopoulou T., Georgiades A., Kalidindi S., Kravariti E., Murray R.M., Murphy D.G., Craig M.C., Catani M. (2015). Age-related differences and heritability of the perisylvian language networks. J. Neurosci., 35(37), 12625-12634.

Carey, S., Bartlett, E. (1978). Acquiring a single new word. Proceedings of the Stanford Child Language Conference, 15, 17-29.

Carey, L.M., Abbott, D.F., Egan, G.F., Bernhardt, J., Donnan, G.A. (2005). Motor impairment and recovery in the upper limb after stroke: behavioral and neuroanatomical correlates. Stroke, 36(3), 625-629.

Carlson, H.L., Sugden, C., Brooks, B.L., Kirton, A. (2019). Functional connectivity of language networks after perinatal stroke. NeuroImage: Clinical, 101861.

Catani, M., Jones, D.K., Ffytche, D.H. (2005). Perisylvian language networks of the human brain. Ann. Neurol. 57, 8-16.

Catani, M., Bambini, V. (2014). A model for social communication and language evolution and development (SCALED). Current Opinion in Neurobiology, 28, 165-171.

Catani, M., De Schotten, M.T. (2008). A diffusion tensor imaging tractography atlas for virtual in vivo dissections. Cortex, 44(8), 1105-1132. 
Ciccarelli, O., Catani, M., Johansen-Berg, H., Clark, C., Thompson, A. (2008). Diffusion based tractography in neurological disorders: concepts, applications, and future developments. Lancet Neurology, 7, 715-727.

Crinion, J., Ashburner, J., Leff, A., Brett, M., Price, C., Friston, K. (2007). Spatial normalization of lesioned brains: performance evaluation and impact on fMRI analyses. Neuroimage, 37, 866-875.

Cunillera, T., Càmara, E., Toro, J.M., Marco-Pallares, J., Sebastián-Galles, N., Ortiz, H., Pujol, J., Rodríguez-Fornells, A. (2009). Time course and functional neuroanatomy of speech segmentation in adults. Neuroimage, 48(3), 541-553.

Dehaene-Lambertz, G., Dehaene, S., Hertz-Pannier, L. (2002). Functional neuroimaging of speech perception in infants. Science 298:2013-2015.

Dehaene-Lambertz, G., Hertz-Pannier, L., Dubois, J., Mériaux, S., Roche, A., Sigman, M., Dehaene, S. (2006). Functional organization of perisylvian activation during presentation of sentences in preverbal infants. Proceedings of the National Academy of Sciences USA, 103(38), $14240-14245$.

Dehaene-Lambertz, G., Spelke, E.S. (2015). The infancy of the human brain. Neuron, 88(1), 93-109.

Dehaene-Lambertz, G. (2017). The human infant brain: A neural architecture able to learn language. Psych. Bull. Rev., 24(1), 48-55.

Dell'acqua, F., Scifo, P., Rizzo, G., Catani, M., Simmons, A., Scotti, G., Fazio, F, (2010). A modified damped Richardson-Lucy algorithm to reduce isotropic background effects in spherical deconvolution. NeuroImage, 49(2), 1446-1458.

Demir, O.E., Levine, S.C., Goldin-Meadow, S. (2010). Narrative skill in children with early unilateral brain injury: a posible limit to functional plasticity. Dev. Sci., 13(4), 636-647.

Demir, Ö., Fisher, J.A., Goldin-Meadow, S., Levine, S.C. (2013). Narrative processing in typically developing children and children with early unilateral brain injury: seeing gesture matters. Dev. Psychol, 50(3), 815-828.

Demir, Ö.E., Rowe, M.L., Heller, G., Goldin-Meadow, S., Levine, S.C. (2015). Vocabulary, syntax, and narrative development in typically developing children and children with early unilateral brain injury: early parental talk about the "there-and-then" matters. Dev. Psychol, 51(2), 161-175.

Dick, A.S., Raja Beharelle, A., Solodkin, A., Small, S.L. (2013). Inter-hemispheric functional connectivity following prenatal or perinatal brain injury predicts receptive language outcome. J Neurosci 33(13), 5612-5625.

Di Pino, G., Pellegrino, G., Assenza, G., Capone, F., Ferreri, F., Formica, D., et al. (2014). Modulation of brain plasticity in stroke: a novel model for neurorehabilitation. Nat. Rev. Neurol., 10(10), 597.

Dubois, J., Dehaene-Lambertz, G., Perrin, M., Mangin, J. F., Cointepas, Y., Duchesnay, E., Le Bihan, D., Hertz-Pannier, L. (2008). Asynchrony of the early maturation of white matter bundles in healthy infants: quantitative landmarks revealed noninvasively by diffusion tensor imaging. Human brain mapping, 29(1), 14-27.

Dubois, J., Poupon, C., Thirion, B., Simonnet, H., Kulikova, S., Leroy, F., HertzPannier, L., Dehaene-Lambertz, G. (2015). Exploring the early organization and maturation of linguistic pathways in the human infant brain. Cerebral Cortex, 26(5), 2283-2298. 
Dunn, L.M., Dunn, L.M., Arribas, D. (1997). PPVT-III. Peabody picture vocabulary test. Spanish adaptation.

Fillmore, P.T., Richards, J.E., Phillips-Meek, M.C., Cryer, A., Stevens, M. (2015). Stereotaxic Magnetic Resonance Imaging Brain Atlases for Infants from 3 to 12 Months. Dev Neurosci, 37(6), 515-532.

François, C., Ripollés, P., Bosch, L., Garcia-Alix, A., Muchart, J., Sierpowska, J., et al. (2016). Language learning and brain reorganization in a 3.5-year-old child with left perinatal stroke revealed using structural and functional connectivity. Cortex 77, 95-118.

François, C., Ripollés, P., Ferreri, L., Muchart, J., Sierpowska, J., Fons, C., et al. (2019). Right structural and functional reorganization in 4-year-old children with perinatal arterial ischemic stroke predict language production. eNeuro.

Friederici, A.D., Bahlmann, J., Heim, S., Schubotz, R.I., Anwander, A. (2006). The brain differentiates human and non-human grammars: functional localization and structural connectivity. PNAS, 103, 2458-2463.

Friederici, A.D., Kotz, S.A., Scott, S.K., Obleser, J. (2010). Disentangling syntax and intelligibility in auditory language comprehension. Human Brain Mapping, 31, 448-457.

Fuentes, A., Deotto, A., Desrocher, M., deVeber, G., Westmacott, R. (2014). Determinants of cognitive outcomes of perinatal and childhood stroke: A review. Child Neuropsychol, 1-38.

Goldfield, B.A., Reznick, J.S. (1990). Early lexical acquisition: rate, content, and the vocabulary spurt. Journal of Child Language, 17, 171-183.

Grefkes, C., Nowak, D.A., Eickhoff, S.B., Dafotakis, M., Küst, J., Karbe, H., et al. (2008). Cortical connectivity after subcortical stroke assessed with functional magnetic resonance imaging. Ann. Neurol., 63(2), 236-246.

Guzzetta, A., Pecini, C., Biagi, L., Tosetti, M., Brizzolara, D., Chilosi, A., et al. (2008). Language organisation in left perinatal stroke. Neuropediatrics, 39(03), 157-163.

Hickok, G., Poeppel, D. (2004). Dorsal and ventral streams: a framework for understanding aspects of the functional anatomy of language. Cognition 92, 67-99.

Hladký, V., Havlíček, J. (2013). Was Tinbergen an Aristotelian? Comparison of Tinbergen's four whys and Aristotle's four causes. Human Ethology Bulletin, 28(4), 3-11.

Hutton, J.S., Dudley, J., Horowitz-Kraus, T., DeWitt, T., Holland, S.K. (2018). Differences in functional brain network connectivity during stories presented in audio, illustrated, and animated format in preschool-age children. Brain imaging and behavior, 1-12.

Ilves, P., Tomberg, T., Kepler, J., Laugesaar, R., Kaldoja, M.L., Kepler, K., Kolk, A. (2014). Different plasticity patterns of language function in children with perinatal and childhood stroke. Journal of child neurology, 29(6), 756-764.

Ilves, N., Ilves, P., Laugesaar, R., Juurmaa, J., Männamaa, M., Lõo, S., et al. (2016). Resting-state functional connectivity and cognitive impairment in children with perinatal stroke. Neural plasticity, 2016, 2306406.

Jacola, L.M., Schapiro, M.B., Schmithorst, V.J., Byars, A.W., Strawsburg, R.H., Szaflarski, J.P., et al. (2006). Functional magnetic resonance imaging reveals atypical language organization in children following perinatal left middle cerebral artery stroke. Neuropediatrics, 37(1):46-52. 
Jaillard, A., Martin, C.D., Garambois, K., Lebas, J.F., Hommel, M. (2005). Vicarious function within the human primary motor cortex? A longitudinal fMRI stroke study. Brain, 128(5), 1122-1138.

Jenkinson, M., Beckmann, C.F., Behrens, T.E., Woolrich, M.W., Smith, S.M. (2012). FSL. Neuroimage, 62, 782-790.

Jansen, A., Flöel, A., Van Randenborgh, J., Konrad, C., Rotte, M., Förster, A.F., et al. (2005). Crossed cerebro-cerebellar language dominance. Human brain mapping, 24(3), 165172.

Kirton, A., Deveber, G., Pontigon, A.M., Macgregor, D., Shroff, M. (2008). Presumed perinatal ischemic stroke: vascular classification predicts outcomes. Ann. Neurol., 63, 436-443.

Knickmeyer, R.C., Gouttard, S., Kang, C., Evans, D., Wilber, K., Smith, J.K., Hamer, R.M., Lin, W., Gerig, G., Gilmore, J.H. (2008). A structural MRI study of human brain development from birth to 2 years. Journal of Neuroscience, 28(47), 12176-12182.

Kuhl, P.K., Meltzoff, A.N. (1996). Infant vocalizations in response to speech: vocal imitation and developmental change. The Journal of the Acoustical Society of America, 100, 2425-2438.

Kuhl P.K., Stevens E., Hayashi A., Deguchi T., Kiritani S., Iverson P. (2006). Infants show facilitation for native language phonetic perception between 6 and 12 months. Developmental Science, 9, 13-21.

Kuhl, P.K., Conboy, B.T., Coffey-Corina, S., Padden, D., Rivera-Gaxiola, M., Nelson, T. (2008). Phonetic learning as a pathway to language: New data and native language magnet theory expanded (NLM-e). Philosophical Transactions of the Royal Society B: Biological Sciences, 363, 979-1000.

Kümmerer, D., Hartwigsen, G., Kellmeyer, P., Glauche, V., Mader, I., Klöppel, S., et al. (2013). Damage to ventral and dorsal language pathways in acute aphasia. Brain, 136, 619-629.

Lebel, C., Beaulieu, C. (2009). Lateralization of the arcuate fasciculus from childhood to adulthood and its relation to cognitive abilities in children. Human brain mapping, 30(11), 3563-3573.

Le Bihan, D. (2003). Looking into the functional architecture of the brain with diffusion MRI. Nat. Rev. Neuro., 4(6), 469.

Leroy, F., Glasel, H., Dubois, J., Hertz-Pannier, L., Thirion, B., Mangin, J.F., DehaeneLambertz. G. (2011). Early maturation of the linguistic dorsal pathway in human infants. $J$. Neurosci, 31(4), 1500-1506.

Liberman, A.M., Mattingly, I.G. (1985): The motor theory of speech perception revised. Cognition 21, 1-36.

Lidzba, K., Wilke, M., Staudt, M., Krägeloh-Mann, I., Grodd, W. (2008). Reorganization of the cerebro-cerebellar network of language production in patients with congenital left-hemispheric brain lesions. Brain lang, 106(3), 204-210.

Lidzba, K., Küpper, H., Kluger, G., Staudt, M. (2017a). The time window for successful right-hemispheric language reorganization in children. Eur J Paediatr Neurol, 21(5), 715-721.

Lidzba, K., deHaan, B., Wilke, M., Krägeloh-Mann, I., Staudt, M. (2017b). Lesion characteristics driving right-hemispheric language reorganization in congenital left-hemispheric brain damage. Brain Lang, 173, 1-9. 
Liu, Z, Li., Y, Zhang, X., Savant-Bhonsale, S., Chopp, M. (2008). Contralesional axonal remodeling of the corticospinal system in adult rats after stroke and bone marrow stromal cell treatment. Stroke, 39(9), 2571-2577.

López-Barroso, D., Catani, M., Ripollés, P., Dell’Acqua, F., Rodríguez-Fornells, A., de Diego-Balaguer, R. (2013). Word learning is mediated by the left arcuate fasciculus. PNAS, $110,13168-13173$.

MacDougall-Shackleton, S.A. (2011). The levels of analysis revisited. Philosophical Transactions of the Royal Society of London B: Biological Sciences, 366(1574), 2076-2085.

Mesgarani, N., Cheung, C., Johnson, K., Chang, E.F. (2014). Phonetic feature encoding in human superior temporal gyrus. Science, $343,1006-1010$.

Murias, K., Brooks, B., Kirton, A., Iaria, G. (2014). A Review of Cognitive Outcomes in Children Following Perinatal Stroke. Dev. Neuropsychol., 39(2), 131-57. 158.

Nelson, K.B., Lynch, J.K. (2004). Stroke in newborn infants. Lancet Neurol 3(3):150-

Northam, G.B., Adler, S., Eschmann, K.C., Chong, W.K., Cowan, F.M., Baldeweg, T. (2018). Developmental conduction aphasia after neonatal stroke. Ann. Neurol., 83(4), 664-675.

Norton, A., Zipse, L., Marchina, S., \& Schlaug, G. (2009). Melodic intonation therapy. ANYAS, 1169(1), 431-436.

Núñez, C., Arca, G., Agut, T., Stephan-Otto, C., García-Alix, A. (2019). Precise neonatal arterial ischemic stroke classification with a three-dimensional map of the arterial territories of the neonatal brain. Pediatric Research, 1-7.

Ouyang, M., Dubois, J., Yu, Q., Mukherjee, P., Huang, H. (2019). Delineation of early brain development from fetuses to infants with diffusion MRI and beyond. Neuroimage, 185, 836-850.

Paldino, M.J., Hedges, K., Gaab, N., Galaburda, A.M., Grant, P.E. (2015). Failure to identify the left arcuate fasciculus at diffusion tractography is a specific marker of language dysfunction in pediatric patients with Polymicrogyria. Behav. Neurol., 351-391.

Peñaloza, C., Benetello, A., Tuomiranta, L., Heikius, I.M., Järvinen, S., Majos, M.C., et al. (2015). Speech segmentation in aphasia. Aphasiology, 29, 724-743

Peñaloza, C., Mirman, D., Tuomiranta, L., Benetello, A., Heikius, I. M., Järvinen, S., et al. (2016). Novel word acquisition in aphasia: Facing the word-referent ambiguity of natural language learning contexts. Cortex, 79, 14-31.

Peñaloza, C., Mirman, D., Cardona, P., Juncadella, M., Martin, N., Laine, M., Rodriguez-Fornells, A. (2017). Cross-situational word learning in aphasia. Cortex, 93, 12-27.

Perani, D., Saccuman, M.C., Scifo, P., Anwander, A., Spada, D., Baldoli, C., Poloniato, A., Lohmann, G., Friederici, A.D. (2011). Neural language networks at birth. Proceedings of the National Academy of Sciences USA, 108(38), 16056-16061.

Price, C.J. (2012). A review and synthesis of the first 20 years of PET and fMRI studies of heard speech, spoken language and reading. NeuroImage 62, 816-847.

Raja-Beharelle, A., Dick, A.S., Josse, G., Solodkin, A., Huttenlocher, P.R., Levine, S.C., Small, S.L. (2010). Left hemisphere regions are critical for language in the face of early left focal brain injury. Brain 133(Pt6), 1707-1716. 
Reilly, J.S., Wasserman, S., Appelbaum, M. (2013). Later language development in narratives in children with perinatal stroke. Dev. Sci., 16, 67-83.

Richards, J.E., Sanchez, C., Phillips-Meek, M., Xie, W. (2015). A database of ageappropriate average MRI templates. NeuroImage, 124(Pt B), 1254-1259.

Ripolles, P., Marco-Pallares, J., de Diego-Balaguer, R., Miro, J., Falip, M., Juncadella, M., Rubio, F., Rodriguez-Fornells, A. (2012). Analysis of automated methods for spatial normalization of lesioned brains. Neuroimage, 60, 1296-1306.

Rodríguez-Fornells, A., Cunillera, T., Mestres-Missé, A., De Diego-Balaguer, R. (2009). Neurophysiological mechanisms involved in language learning in adults. Phil. Trans. Roy. Soc. B: Biol. Sci., 364, 3711-3735.

Rojkova, K., Volle, E., Urbanski, M., Humbert, F., Dell'Acqua, F., Thiebaut de Schotten, M. (2016). Atlasing the frontal lobe connections and their variability due to age and education: a spherical deconvolution tractography study. Brain Struct Funct, 221, 1751-1766.

Romeo, R.R., Leonard, J.A., Robinson, S.T., West, M.R., Mackey, A.P., Rowe, M.L., Gabrieli, J.D. (2018). Beyond the 30-Million-Word Gap: Children's Conversational Exposure Is Associated With Language-Related Brain Function. Psychological science, 29(5), 700-710.

Sanchez, C.E., Richards, J.E., Almli, C.R. (2011). Neurodevelopmental MRI brain templates for children from 2 weeks to 4 years of age. Dev Psychobiol, 54(1), 77-91.

Salvan, P., Tournier, J.D., Batalle, D., Falconer, S., Chew, A., Kennea, N., et al. (2017). Language ability in preterm children is associated with arcuate fasciculi microstructure at term. $H B M, 38(8), 3836-3847$.

Sanchez, C.E., Richards, J.E., Almli, C.R. (2012). Age-specific MRI templates for pediatric neuroimaging. Dev Neuropsychol. 37, 379-399.

Saur, D., Kreher, B.W., Schnell, S., Kümmerer, D., Kellmeyer, P., Vry, M.S., et al. (2008). Ventral and dorsal pathways for language. PNAS, 105, 18035-18040.

Schaechter, J.D., Fricker, Z.P., Perdue, K.L., Helmer, K.G., Vangel, M.G., Greve, D.N., Makris, N. (2009). Microstructural status of ipsilesional and contralesional corticospinal tract correlates with motor skill in chronic stroke patients. $H B M, 30(11), 3461-3474$.

Schafer, G., Plunkett, K. (1998). Rapid word learning by fifteen-month-olds under tightly controlled conditions. Child Development, 69(2), 309-320.

Schmahmann, J.D., Pandya, D.N., Wang, R., Dai, G., D'Arceuil, H. E., de Crespigny, A.J., Wedeen, V.J. (2007). Association fibre pathways of the brain: parallel observations from diffusion spectrum imaging and autoradiography. Brain, 130, 630-653.

Smith, S.M., Jenkinson, M., Johansen-Berg, H., Rueckert, D., Nichols, T.E., Mackay, C.E., Watkins, K.E., Ciccarelli, O., Cader, M.Z., Matthews, P.M., Behrens, T.E. (2006). Tractbased spatial statistics: voxelwise analysis of multi-subject diffusion data. Neuroimage, 31, $1487-1505$.

Staudt, M., Lidzba, K., Grodd, W., Wildgruber, D., Erb, M., Krägeloh-Mann, I. (2002). Right-hemispheric organization of language following early left-sided brain lesions: functional MRI topography. NeuroImage 16(4), 954-967.

Stephan-Otto, C., Núñez, C., Arca, G., Agut, T., García-Alix, A. (2017). Threedimensional map of neonatal arterial ischemic stroke distribution from early multimodal brain imaging. Stroke, 48(2), 482-485. 
Stiles, J., Reilly, J., Paul, B., Moses, P. (2005). Cognitive development following early brain injury: evidence for neural adaptation. TICS., 9(3), 136-143.

Takahashi, E., Folkerth, R.D., Galaburda, A.M., Grant, P.E. (2011). Emerging cerebral connectivity in the human fetal brain: an MR tractography study. Cerebral cortex, 22(2), 455464.

Thiebaut de Schotten, M., Ffytche, D.H., Bizzi, A., Dell'Acqua, F., Allin, M., Walshe, M., et al. (2011). Atlasing location, asymmetry and inter-subject variability of white matter tracts in the human brain with MR diffusion tractography. NeuroImage, 54(1), 49-59.

Tillema, J.M., Byars, A.W., Jacola, L.M., Schapiro, M.B., Schmithorst, V.J., Szaflarski, J.P., Holland, S.K. (2008). Cortical reorganization of language functioning following perinatal left MCA stroke. Brain Lang 106(3), 184-194.

Tinbergen, N. (1963). On aims and methods of ethology. Zeitschrift für Tierpsychologie, 20, 410-429.

Weiss-Croft, L.J., Baldeweg, T. (2015). Maturation of language networks in children: A systematic review of 22 years of functional MRI. NeuroImage, 123, 269-281.

Wernicke, C. (1874). Der Aphasische Symptomencomplex. Ein Psychologische Studie auf Anatomischer Basis. Breslau: Cohn and Weiger.

Westmacott, R., Askalan, R., MacGregor, D., Anderson, P., Deveber, G. (2010). Cognitive outcome following unilateral arterial ischaemic stroke in childhood: effects of age at stroke and lesion location. Dev. Med. Child Neurology., 52, 386-393.

Wilson, S.M., Galantucci, S., Tartaglia, M.C., Rising, K., Patterson, D.K., Henry, M.L., Ogar, J.M., DeLeon, J., Miller, B.L., Gorno-Tempini, M.L. (2011). Syntactic processing depends on dorsal language tracts. Neuron, 72(2), 397-403.

Yu, Q., Peng, Y., Kang, H., Peng, Q., Ouyang, M., Slinger, M., Hu, D., Shou, H., Fang, F., Huang, H. (2019). Differential White Matter Maturation from Birth to 8 Years of Age. Cerebral Cortex. pii: bhz268. doi: 10.1093/cercor/bhz268. [Epub ahead of print]

Zhang, J., Evans, A., Hermoye, L., Lee, S.K., Wakana, S., Zhang, W., Donohue, P., Miller, M.I., Huang, H., Wang, X., van Zijl, P.C., Mori, S. (2007). Evidence of slow maturation of the superior longitudinal fasciculus in early childhood by diffusion tensor imaging. Neuroimage, 38(2), 239-247.

Zäske, R., Awwad Shiekh Hasan, B., Belin, P. (2017). It doesn't matter what you say: FMRI correlates of voice learning and recognition independent of speech content. Cortex, 94, $100-112$. 